\title{
Effect of RF magnetron sputtering parameters on the optimization of the discharge capacity of ternary lithium oxide thin films
}

\section{Daniel Andres Sanchez Lopez}

UEL: Universidade Estadual de Londrina

Luciana Gomes Chagas

Johnson Matthey Process Technologies Inc

Aline Domingues Batista

UEL: Universidade Estadual de Londrina

Maria Gabriella Detone Guaita

UEL: Universidade Estadual de Londrina

Luís Henrique Cardozo Amorin

Bahia's Federal Education Science and Technology Centre - Camacari Campus: Centro Federal de

Educacao Ciencia e Tecnologia da Bahia - Campus Camacari

\section{Paulo Rogério Catarini da Silva}

UEL: Universidade Estadual de Londrina

Gustavo Yamanishi

UEL: Universidade Estadual de Londrina

Dimas Augusto Morozin Zaia

UEL: Universidade Estadual de Londrina

Henrique de Santana

UEL: Universidade Estadual de Londrina

Alexandre Urbano ( $\sim$ aurbano@uel.br)

Universidade Estadual de Londrina https://orcid.org/0000-0002-5057-1982

\section{Research Article}

Keywords: Thin film, RF magnetron sputtering, lithium-ion battery, factorial design, micro-batteries

Posted Date: May 27th, 2021

DOI: https://doi.org/10.21203/rs.3.rs-363697/v1

License: (c) (1) This work is licensed under a Creative Commons Attribution 4.0 International License.

Read Full License 


\section{Abstract}

The increasing demand for lithium-ion batteries has stimulated the investigation of new compounds in order to reduce the costs and the toxicity of their cathodes. Materials constituted of ternary lithiated oxide compounds are a successful alternative to cobalt-rich cathodes. The main disadvantage of ternary compound materials (TCM) is that the maximum amount of electrical charge is only achieved at high redox potentials, a limiting factor if we consider the current development in electrolyte technology. In this work, we investigated the influence of sputtering deposition parameters on the charge capacity of TCM thin films, restraining their electrochemical potential to conventional values. To do so, we analyzed the impact that small changes in crystalline and morphological structures have on the charge capacity at low cell potentials. For this, we performed the RF magnetron sputtering of TCM thin films, and carried out a factorial design of experiments to investigate their electrochemical properties, while limiting the charging potential to $4.20 \mathrm{~V}$ vs. $\mathrm{Li} \mathrm{Li}^{+}$. The films were deposited onto a rigid and conductive substrate with different parameters (power and pressure at room temperature). Electrochemical results showed that the discharge capacity is strongly influenced by the deposition parameters, reaching $250 \mathrm{mAh} \mathrm{g}^{-1}$ even at $4.20 \mathrm{~V} \mathrm{vs}$. Li. This value is superior to the ones of the conventional cobalt cathode and the bulk ternary electrode. Both deposition parameters exhibited a synergic dependency, which means that they need to be simultaneously varied for a response optimization. The discharge capacity of the analyzed samples was highly affected by the surface morphology of the film and its crystallographic properties, and not by its elemental composition. High discharge capacity was obtained without additional thermal treatments, which favors the manufacture of films over polymeric substrates for future electronic applications.

\section{Introduction}

Among all transition metal oxides used as cathode material in lithium-ion batteries, the lithium cobalt oxide ( $\mathrm{LiCOO}_{2}$, LCO) stands out due to its high discharge capacity $\left(140 \mathrm{mAhg}^{-1}\right)$, specific energy (250 Whkg $\left.{ }^{-1}\right)$, good cycling stability and easy production. This compound was originally synthesized by Mizushima and Goodenough [1] and, since the 1990s, it has been widely employed in the composition of commercial rechargeable lithium-ion batteries (LIBs). However, natural cobalt reserves are scarce and concentrated in a few regions of the planet, which not only makes the technology more expensive, but also unfeasible.

After several studies on more abundant transition metals such as nickel, manganese and their mixtures $\left(\mathrm{LiNiO}_{2}, \mathrm{Li}_{2} \mathrm{MnO}_{4}, \mathrm{LiNi}_{0,5} \mathrm{Mn}_{0,5} \mathrm{O}_{2}, \mathrm{LiNi}_{0,5} \mathrm{Co}_{0,5} \mathrm{O}_{2}\right.$, etc.) [2-5] for replacing cobalt, Ohzuku et al [6] suggested $\mathrm{LiNi}_{1 / 3} \mathrm{Mn}_{1 / 3} \mathrm{Co}_{1 / 3} \mathrm{O}_{2}$ (NMC333) as a potential candidate for substituting pure LCO. This compound presents a theoretical capacity of $280 \mathrm{mAh} \mathrm{g}^{-1}$, with good thermal and structural stability, and has a lower cost than LCO $[7,8]$. At a closer look, the partial substitution of Co by Ni and Mn decreases the toxicity and the costs of the battery while increasing its thermal stability and cell potential, respectively due to $\mathrm{Mn}$ and $\mathrm{Ni}[9-11]$, but does not change the LCO crystallographic structure (rhombohedral a-NaFeO,$R-3 m$ ). In NMC333, the valence states of the elements are $\mathrm{Li}^{+}$ 
$\left(\mathrm{Ni}^{2+} \mathrm{Co}^{3+} \mathrm{Mn}^{4+} \mathrm{O}_{2}{ }^{2-}\right.$. During the charging process, $\mathrm{Ni}^{2+}$ and $\mathrm{Co}^{3+}$ cations are electrically activated, causing the oxidation of $\mathrm{Ni}^{2+} \rightarrow \mathrm{Ni}^{4+}$ and $\mathrm{Co}^{3+} \rightarrow \mathrm{Co}^{4+}$ [7]. The manganese ion remains with an unchanged valence of $4^{+}$and does not take part in the redox reactions. $\ln \mathrm{Li}_{(1-\mathrm{x})}\left(\mathrm{Ni}_{1 / 3} \mathrm{Mn}_{1 / 3} \mathrm{Co}_{1 / 3}\right) \mathrm{O}_{2}$, the amount of lithium ions that can be de-intercalated is close to $x=1$, resulting in a discharge capacity of $270 \mathrm{mAhg}^{-1}$, and a gravimetric energy of almost $800 \mathrm{Whkg}^{-1}[7,12]$. Some stoichiometry variations of the metals composing the ternary compound materials (TCM) improve their physical properties and decrease their cost, being Ni-rich phases good examples of modern TCM, $\left(\mathrm{Li}_{1}\left(\mathrm{Ni}_{0.6} \mathrm{Mn}_{0.2} \mathrm{Co}_{0.2}\right) \mathrm{O}_{2}\right.$, $\left.\mathrm{Li}_{1}\left(\mathrm{Ni}_{0.8} \mathrm{Mn}_{0.1} \mathrm{Co}_{0.1}\right) \mathrm{O}_{2}\right)[13,14]$. However, in order to reach excellent performance, the TCM electrochemical oxidation potential should exceed $4.20 \mathrm{~V} \mathrm{vs.} \mathrm{Li}_{\mathrm{iLi}}{ }^{+}$, improving both the discharge capacity and the gravimetric energy, which causes, among other problems, the dissolution of metal ions and the degradation of commercially used electrolytes [10,15]. An alternative to maintain the high discharge capacity while reducing the operating voltage is to increase the Mn ratio in the TCM, since the redox potential of the $\mathrm{Mn}^{3+} / \mathrm{Mn}^{4+}$ pair (in a e electronic state) is lower when compared to the ones of $\mathrm{Ni}^{2+} / \mathrm{Ni}^{3+}, \mathrm{Ni}^{3+} / \mathrm{Ni}^{4+}$ and $\mathrm{Co}^{3+} / \mathrm{Co}^{4+}$ (all of them in $\mathrm{t}_{2 \mathrm{~g}}$ ) [16]. In addition to their electronic and stoichiometric issues, TCMs are ionic intercalation compounds and their crystalline structure must be well-ordered to facilitate ion mobility $\left(\mathrm{Li}^{+}\right)$. For this reason, the majority of synthesis routes require thermal treatments at high temperatures, ranging from 700 to $900{ }^{\circ} \mathrm{C}[17,18]$.

The present study, embedded in an approach encompassing a flexible, all-solid-state lithium-ion battery for microelectronic applications, aims to develop cathodic materials in the TCM system, by employing thin-film technologies. Our main goal is to produce films with a high discharge capacity (up to the limit of $4.20 \mathrm{~V} \mathrm{vs.} \mathrm{Li}_{\mathrm{i}} \mathrm{i}^{+}$), with no need of thermal treatments, in or ex-situ, as a way to preserve future flexible substrates, especially polymeric ones.

Some works in the literature report the development of thin TCM films but, in all analyzed studies, the electrochemical potential exceeded $4.20 \mathrm{~V}$ vs. $\mathrm{Li} \mathrm{I} \mathrm{Li}^{+}[19,20]$. Contrary to such observation, our research will show that a high discharge capacity can be obtained using a Mn-rich TCM thin film electrode, limiting the electrochemical potential to $4.20 \mathrm{~V} \mathrm{vs}$. $\mathrm{Li}_{\text {I }} \mathrm{Li}^{+}$. We managed to achieve this result by building and applying a factorial design of experiments. The factorial design was used as a statistical tool for assisting in the investigation of correlations between variables and response optimization. To do so, we assessed the correlation between pressure and power exerted by the RF magnetron sputtering (RFMS) during the TCM thin film deposition, aiming at the optimization of the electrochemical performance. The experiments were elaborated using a $2^{2}$ factorial design that is further described in the Methodology section. The optimization of cathode materials allows for obtaining the maximum performance, promoting the synthesis of materials with physicochemical characteristics suitable for different applications. For example, the development of flexible lithium-ion batteries (FLIBs) and sodium-ion batteries (SIBs) has been encouraged due to the high demand for portable and wearable electronic devices [21, 22]. 


\section{Methodology}

\subsection{SPUTTERING TARGET}

The sputtering target was produced of synthesized NMC333 powder, pressed into a 2-inch-diameter cylindrical stainless steel cup container with a height of $2 \mathrm{~mm}$ and a wall thickness of $1 \mathrm{~mm}$. The NMC333 powder was synthesized via sol-gel method [23], with lithium, nickel, manganese and cobalt acetates as precursor materials (Dinamica Chemistry Contemporary Ltd and Labsynth), in stoichiometric quantities. The gel, obtained by drying the metals-containing solution with citric acid, was pre-calcined at $450^{\circ} \mathrm{C}$ for 6 hours, ground and re-calcined at $700^{\circ} \mathrm{C}$ for 2 hours. The stainless steel container not only provided physical support to the NMC powder, but also increased the thermal conductivity at the base of the target.

\subsection{DEPOSITION PARAMETERS AND STATISTICAL PLANNING}

Lithiated ternary oxide thin films were deposited by Radio Frequency Magnetron Sputtering (RFMS - HHV Auto 500) on a glass substrate initially coated with titanium thin films (50 nm; HHV - Auto 500), and posteriorly coated with aluminum (100 nm; HHV - Auto 306) to enhance electronic conductivity (Fig. 1). The base pressure for chamber cleaning was $2 \times 10^{-6}$ mbar. Titanium was used as an anchoring layer between aluminum and glass.

A $2^{2}$ factorial design of experiments was used to evaluate the correlation between the deposition parameters and the physical/chemical characteristics of the films. The correlation effects $\left(R_{i}\right)$ were calculated in accordance with Eq. (1). This expression is formed with basis on the matrix of constraints $(M)$, which allows for estimating main and interaction effects of the responses $\left(Y_{i}\right)$, obtained through the planned experiments $[24,25]$ :

$$
M^{t} Y=\left[\begin{array}{l}
+1+1+1+1 \\
+1+1-1-1 \\
+1-1+1-1 \\
+1-1-1+1
\end{array}\right]\left[\begin{array}{l}
Y_{1} \\
Y_{2} \\
Y_{3} \\
Y_{4}
\end{array}\right]=\left[\begin{array}{l}
R_{1} \\
R_{2} \\
R_{3} \\
R_{4}
\end{array}\right]
$$

The analyzed deposition parameters were power and deposition pressure, scrutinized in two levels, as shown in Table 1.

Table 1 Variables and levels of the $2^{2}$ factorial design, for TCM thin films deposition by RFMS 


\begin{tabular}{|lllll|}
\hline Sample & $\begin{array}{l}\text { Power } \\
\text { (W) }\end{array}$ & $\begin{array}{l}\text { Deposition Pressure } \\
\text { (mbar) }\end{array}$ & Po & Pr \\
\hline 1 & 200 & $1.35 \times 10^{-2}$ & + & + \\
\hline 2 & 200 & $1.02 \times 10^{-2}$ & + & - \\
\hline 3 & 100 & $1.35 \times 10^{-2}$ & - & + \\
\hline 4 & 100 & $1.02 \times 10^{-2}$ & - & - \\
\hline
\end{tabular}

The NMC333 sputtering was carried out with an analytical AR (White Martins) controlled by a flowmeter, using $100 \mathrm{~W}(-)$ and $200 \mathrm{~W}(+)$ as power limits, and $1.02 \times 10^{-2}$ mbar (-) and $1.35 \times 10^{-2} \mathrm{mbar}(+)$ as pressure limits $(\mathrm{Pr})$ for the deposition. The sputtering plasma was maintained by auto-tuning the impedance of the whole system. The thickness of the films $(100 \mathrm{~nm})$ was monitored in-situ by a quartz crystal microbalance. The mass of the films was estimated with basis on the density of the bulk NMC333 compound $\left(\rho_{\mathrm{NMC} 333}=3.7 \mathrm{~g} / \mathrm{cm}^{3}\right)$.

\subsection{CRYSTALLOGRAPHY}

The X-ray diffraction analyses of NMC333 powder and TCM films was performed using a Panalytical XPert PRO MPD diffractometer, equipped with a Bragg-Brentano geometry of CuKa radiation source ( $\lambda=$ $1.5419 \AA$ ) , positioned in an angular step of $0.02^{\circ}$ with 2 seconds per step, in a $2 \theta$ range of 10 to 90 degrees. The powder diffractogram was performed through the refinement of the crystalline structures via Rietveld's method, using the Xpert Highscore Plus program. The Scherrer equation was employed to evaluate the crystallite size of the films, using a Gaussian function for estimating the full width at half maximum (FWHM). Polycrystalline silicon was used as instrumental-standard sample to determine the instrumental broadening effect factor. Errors were estimated based on FWHM deviation.

\subsection{STOICHIOMETRY}

Both the target and the film stoichiometries were carried out by X-ray fluorescence (XRF) in a Shimadzu EDX-720 energy-dispersive spectrometer (Shimadzu Co., Kyoto, Japan). The spectrometer was equipped with an Rh tube and a Si $(\mathrm{Li})$ detector, with an active window of $25 \mathrm{~mm}^{2}$ and $0.5 \mathrm{~mm}$ thick, having a 135 $\mathrm{eV}$ resolution at $\mathrm{Mn}-\mathrm{K}$ line. The measurement time was 500 seconds.

\subsection{SURFACE MORPHOLOGY}

The topography and the surface roughness of the films were characterized by an atomic force microscope with Nanosurf system (flexAFM), consisting of a modular exploration probe that can be updated to improve the measurement capacity in real-time. The measurements were performed employing contact force mode, through a flexible cantilever (TAP1990AL) that provided a sweep of 5 $\mu \mathrm{m}^{2}$, with 512 points per scan line.

\subsection{FOURIER TRANSFORM INFRA-RED SPECTROSCOPY}


Fourier-Transform Infra-Red (FTIR) spectra ranging from 400 to $4000 \mathrm{~cm}^{-1}$ were obtained using a PerkinElmer Frontier spectrometer with Attenuated Total Reflectance (ATR). The Fourier Transform was performed over 16 scans, providing an averaged single spectrum as result.

\subsection{ELECTROCHEMICAL PERFORMANCE}

The electrochemical performance was assessed via chronopotentiometry, using a multi-channel potentiostat of Arbin Instruments (MSTAT 8000/BT 2000). In the analysis, we used a three-electrode cell with a counter electrode (CE), a lithium metal wire as a reference electrode (RE), and a TCM film as a working electrode (WE). The employed electrolyte was $\mathrm{LiClO}_{4} / \mathrm{EC} / \mathrm{DMC}(1 \mathrm{~mol} / \mathrm{L})$, and all utilized chemical reagents were produced by Sigma Aldrich. The cell was assembled at room temperature, under an inert atmosphere, inside an MBRAUN glove box with water and oxygen concentrations below $5 \mathrm{ppm}$. Measurements were performed at a potential range between 2.20 and $4.20 \mathrm{~V}\left(\mathrm{vs}\right.$. $\left.\mathrm{Li}^{+} \mid \mathrm{Li}\right)$, with a current density of $15.0 \mathrm{~mA} \mathrm{~g}^{-1}$, for 9 cycles.

\section{Results And Discussions}

\subsection{CRYSTALLOGRAPHY}

Figure 2a shows the diffractogram of the NMC333 powder used to produce the target. Narrow and intense peaks indicate a compound with a high order of crystallinity, indexed to a a- $\mathrm{NaFeO}_{2}$ hexagonal layered structure, with space group $R-3 m[7,9,26]$. Based on the diffractogram and applying the Scherrer equation, while using silicon as an instrumental-standard sample for determining the FWHM value, the crystallite size of the target was estimated in $24.5 \mathrm{~nm}$ [17].

The diffraction patterns of as-deposited TCM films under different conditions are shown in Fig. 2b. All diffractograms exhibited three peaks: the first, around $35^{\circ}(2 \theta)$, belonging to the Ti phase; the second, at $38.0^{\circ}(2 \theta)$, corresponding to the cubic phase of a conductor aluminum film with preferred orientation towards the direction of [111]. The highest intensity peak of aluminum can be attributed to the structure factor $\left(\mathrm{F}_{(\mathrm{hkl})}\right)$ of an FCC-type lattice, which implies an increase in the intensity of the scattered X-rays. The third, at $44.0^{\circ}(2 \theta)$, is related to the TCM film whose Miler index is (104). The set of planes appears to be spatially oriented in parallel to the substrate, in the [104] direction, and his preferential orientation may be due to the minimization of the surface energy, since these films have a lesser thickness $[20,27,28]$.

The crystallite size of the TCM films are shown in Table 2. Table 3, by its turn, presents the correlations between the deposition parameters (power and pressure). It can be seen that the power has a subtle, but statistically significant, effect on the size of the crystallite, while the pressure does not seem to influence this response. The positive value of the main effect related to power indicates that an increase in this factor causes an increase in the crystallite size. Such occurrence is expected because, with the rise of the sputtering power, the atoms ejected from the target reach the substrate with greater kinetic energy, 
favoring the crystallization of the film. The pressure main effect and the incidence of interaction values close to zero indicate that these effects exert no influence on the crystallite size.

Table 2

Crystallite size calculated by the Scherrer equation. The value of the $\mathrm{k}$ factor chosen was 0.9 and the error was estimated from the FWHM

\begin{tabular}{|ll|}
\hline Sample & Crystallite size $(\mathrm{nm})$ \\
\hline $\mathrm{Po}+\mathrm{Pr}+$ & $4.93 \pm 0.53$ \\
\hline $\mathrm{Po}-\mathrm{Pr}-$ & $3.51 \pm 0.57$ \\
\hline $\mathrm{Po}+\mathrm{Pr}-$ & $4.85 \pm 0.32$ \\
\hline $\mathrm{Po}-\mathrm{Pr}+$ & $3.21 \pm 0.15$ \\
\hline
\end{tabular}

Table 3

Table of effects for the $2^{2}$ factorial design of crystallite sizes

\begin{tabular}{|lll|}
\hline & Effects & Crystallite size $(\mathrm{nm})$ \\
\hline \multirow{2}{*}{ Main Effects } & Power & $1.53 \pm 0.1$ \\
\cline { 2 - 3 } & Pressure & $-0.11 \pm 0.1$ \\
\hline \multirow{2}{*}{ Interaction } & Power-Pressure & $0.19 \pm 0.1$ \\
\hline
\end{tabular}

The intrinsic crystallinity of the film obtained via RFMS deposition is an important factor, which demonstrates the feasibility of this process in obtaining crystalline films. Furthermore, such factor is crucial for eliminating post-thermal treatments, allowing for the manufacture of electrodes especially designed for flexible micro-devices, since they do not support high temperatures.

\subsection{ElemeNtal quantification}

Table 4 presents elemental quantitative results obtained from the X-ray fluorescence of the ternary films. Through the analysis of the data, it is possible to notice that the films presented a stoichiometry different from that of the target. All TCM films showed a high concentration (in mol \%) of manganese (45\%), an intermediate concentration of cobalt (30\%), and a low concentration of nickel (25\%). The discrepancy between stoichiometry values $(1 / 3: 1 / 3: 1 / 3)$ can be due to the different sputtering yields for each atomic species. According to the factorial planning, and considering that no specific order was followed during the depositions, XRF results revealed that the deposition parameters (power and pressure) do not have a great impact on the stoichiometry of the films. 
Table 4

Results of energy-dispersive X-ray fluorescence for planned TCM films

\begin{tabular}{|l|lllll|}
\hline Element & $\begin{array}{l}\text { Po+Pr+ } \\
\text { (mol \%) }\end{array}$ & $\begin{array}{l}\text { Po+Pr- } \\
\text { (mol \%) }\end{array}$ & $\begin{array}{l}\text { Po-Pr- } \\
\text { (mol \%) }\end{array}$ & $\begin{array}{l}\text { Po-Pr+ } \\
\text { (mol \%) }\end{array}$ \\
\hline Mn & 44.45 & 44.35 & 43.28 & 42.70 \\
\hline Co & 31.64 & 29.95 & 31.40 & 31.67 \\
\hline $\mathrm{Ni}$ & 26.00 & 25.68 & 25.31 & 25.62 \\
\hline
\end{tabular}

\subsection{ATOMIC FORCE MICROSCOPY}

Figure 3 exhibits the atomic force microscopy (AFM) images of the surface of (a) clean glass - g; (b) titanium-coated glass - $\mathrm{g} / \mathrm{Ti}$; (c) aluminum-coated glass - $\mathrm{g} / \mathrm{Al}$; and (d) glass initially covered with titanium, then by aluminum - $\mathrm{g} / \mathrm{Ti} / \mathrm{Al}$. Titanium was used as an anchoring layer not only due to its strong bond with the oxygen present in the glass substrate, but also due to its small atomic size, close to those of aluminum and silicon, which strengthen the adherence of the aluminum layer, contributing to lower surface tensions. Roughness values are shown in Table 5. The titanium film seems to make surfaces smoother, whether it is deposited on top of glass (b) or under aluminum (d). This effect causes a decrease in the number of dispersion centers for conduction electrons, located in grain boundaries, causing a decrease in the resistivity [29].

Table 5

Substrate roughness calculated with basis on AFM images, using the Gwyddion 2.53 software, in an area of $5 \times 5 \mu m^{2}$

\begin{tabular}{|ll|}
\hline Sample & $\begin{array}{l}\text { Roughness } \\
(\mathrm{nm})\end{array}$ \\
\hline Glass & $1.7 \pm 0.6$ \\
\hline Glass-Ti & $2.0 \pm 0.3$ \\
\hline Glass-Al & $4.2 \pm 0.6$ \\
\hline Glass-Ti-Al & $2.1 \pm 0.5$ \\
\hline
\end{tabular}

AFM images of the glass/Ti/Al/TCM films are shown in Fig. 4, in a way to facilitate the analysis of the influence of deposition parameters on the roughness and on the shape of surface grains. When horizontally comparing the images, we can observe the influence of the power on the morphology of the film, while a vertical comparison allows for an analysis of the influence exerted by the deposition pressure. Roughness values are presented in Table 6 and geometrically interpreted in Fig. 4. Results indicate that the highest roughness value was obtained under $(\mathrm{Po}-\mathrm{Pr}+)$ conditions. Additionally, the main 
effect of power occurs due to the kinetic energy of the ions colliding with the target. An increase in power $(\mathrm{Po}+)$ causes the atoms to be ejected from the target with greater kinetic energy, which leads to a faster coalescence and favors the formation of a flatter surface.

Table 7 shows the analysis concerning the main effect of $\mathrm{Po}$ and $\mathrm{Pr}$, along with the interactions between the two parameters. Power and pressure influenced the roughness response, but the negative value $(-7.2)$ assumed for their interaction not only suggests a synergic effect between them, but also an inversely proportional dependence encompassed by both parameters and the roughness coefficients. Therefore, considering their interdependency, it is not recommended to individually analyze each parameter, i.e., only their main effects. However, we can not neglect the significant main effect of power (-15.3), which indicates a major influence on roughness, but in an inverse mode (should the power increase, the roughness decreases).

\begin{tabular}{|c|c|}
\hline \multicolumn{2}{|c|}{$\begin{array}{c}\text { Table } 6 \\
\text { Roughness of TCM thin } \\
\text { films calculated with } \\
\text { basis on AFM images, } \\
\text { using the Gwyddion } 2.53 \\
\text { software, in an area of } \\
5 \times 5 \mu \mathrm{m}^{2} \\
\end{array}$} \\
\hline Sample & $\begin{array}{l}\text { Roughness } \\
(\mathrm{nm})\end{array}$ \\
\hline $\mathrm{Po}+\mathrm{Pr}+$ & $6.9 \pm 1.2$ \\
\hline Po-Pr- & $14.6 \pm 2.8$ \\
\hline $\mathrm{Po}+\mathrm{Pr}-$ & $6.5 \pm 0.9$ \\
\hline Po-Pr+ & $29.5 \pm 4.7$ \\
\hline
\end{tabular}

Table 7

Table of effects for the $2^{2}$ factorial design of the roughness $(\mathrm{nm})$ of TCM thin films

\begin{tabular}{|lll|}
\hline & Effects & Roughness (nm) \\
\hline \multirow{2}{*}{ Main Effects } & Power & $-15.3 \pm 2.8$ \\
\cline { 2 - 3 } & Pressure & $7.6 \pm 2.8$ \\
Interaction & Power-Pressure & $-7.2 \pm 2.8$ \\
\hline
\end{tabular}

A scanning electron microscopy (SEM), detailed in Fig. 5, revealed that the surface of the films was free from deep cracks, which indicates a good adhesion of the Ti/Al films to the glass substrate. The spherical structures observed in all images differ in diameter, suggesting that pressure was the main acting factor, once $\mathrm{Pr}+$ films presented smaller grains than those of Pr- (vertical analyses). Additionally, if 
we compare the images concerning the deposition power, it is possible to observe that Po + films tend to be smoother and more compact, with feasible alterations in their density. However, no appreciable difference was observed between Po- and Po+ (horizontal analyses). After confronting Po-Pr- and Po + $\mathrm{Pr}$-, it was possible to observe the presence of spheres with a larger diameter when compared to those of the samples of the top row. Furthermore, $\mathrm{Po}+\mathrm{Pr}$ - showed grains linked to each other. $\mathrm{Po}+\mathrm{Pr}+$, by its turn, also presented joint grains, if compared to $\mathrm{Po}-\mathrm{Pr}+$. Such findings are in agreement with the roughness obtained via AFM, showing that these samples are smoother than Po-Pr + and Po-Pr-.

\subsection{FOURIER-TRANSFORM INFRARED SPECTROSCOPY}

Figure 6 shows the FTIR spectra of $\mathrm{Li}\left(\mathrm{Ni}_{1 / 3} \mathrm{Co}_{1 / 3} \mathrm{Mn}_{1 / 3}\right) \mathrm{O}_{2}$ powder and of the films deposited by RFMS, as planned by the factorial design of experiments. Results show that the ternary lithium oxide was successfully formed, as indicated by the characteristic peaks for layered oxides with a- $\mathrm{NaFeO}_{2}$ structure, in a wavenumber range of $800-400 \mathrm{~cm}^{-1}$. Absorption bands localized at $440-420 \mathrm{~cm}^{-1}$ can be attributed to the $\mathrm{Li}-\mathrm{O}$ bond in $\mathrm{LiO}_{6}$ octahedrons [30]. Bands at $642-648 \mathrm{~cm}^{-1}$, by their turn, are result of the asymmetric stretching of $\mathrm{M}-\mathrm{O}(\mathrm{M}=\mathrm{Ni}, \mathrm{Co}, \mathrm{Mn})$, and the band at $525 \mathrm{~cm}^{-1}$ is due to the $\mathrm{O}-\mathrm{M}-\mathrm{O}$ bending $[30,31]$. The $\mathrm{M}-\mathrm{O}$ stretching occurs because the metal occupies an $\left(\mathrm{MO}_{6}\right)$ octahedral site [32-34]. The band at $950 \mathrm{~cm}^{-1}$ can be attributed to the Al-O bound [35], and the band at $870 \mathrm{~cm}^{-1}$ can be related to the $\mathrm{CO}_{3}{ }^{2-}$ out-of-plane bending [36]. Bands at 1613 and $1443 \mathrm{~cm}^{-1}$ can be respectively associated attributed to $\mathrm{COO}^{-}$antisymmetric and symmetric stretches [34,36], probably due to the presence of lithium carbonate. The band at $1613 \mathrm{~cm}^{-1}$ can be attributed to the $0-\mathrm{H}$ bending [31], and the bands at $2850,2920,3165$ and $3563 \mathrm{~cm}^{-1}$ can be associated to the $0-\mathrm{H}$ stretching $[31,34,37]$.

\subsection{ELECTROCHEMICAL CHARACTERIZATION OF NMC333 films}

The obtained open-circuit voltages of the lithium half-cells containing NMC films were: $\mathrm{Po}+\operatorname{Pr}+=3.5 \pm$ $0.2 \mathrm{~V}$, Po-Pr- $=3.5 \pm 0.1 \mathrm{~V}, \mathrm{Po}+\mathrm{Pr}-=3.3 \pm 0.1 \mathrm{~V}$, and $\mathrm{Po}-\mathrm{Pr}+=3.4 \pm 0.1 \mathrm{~V}$. These values are compatible with the ones expected for lithium half-cells containing lithium transition metal oxides.

Figure 7 presents the chronopotentiometric cycles of the films, in a potential range between 2.20 and 4.20 $\mathrm{V}$, at a current density of $15.0 \mathrm{mAg}^{-1}$. Po $+\mathrm{Pr}+$ and Po + Pr- films exhibited lower discharge capacities when compared to those reported for conventional bulk NMC333 electrodes, while Po-Pr- and Po-Pr+ showed a significant improvement in capacity. In general, the obtained discharge capacities were higher than those of conventional cathode composites, which require the addition of binders and electronic conductors $[6,26]$. Furthermore, the attained values were close to the theoretical capacity, showing that all lithium ions could be reversibly de-intercalated from the host material structure. The Po-Pr- sample, on the other hand, showed good reversibility up to the ninth cycle and presented a high discharge capacity $\left(250 \mathrm{mAhg}^{-1}\right)$, even with a cut-off potential of $4.20 \mathrm{~V}$. The increase in the discharge capacity, observed from the first to the ninth cycle, can be attributed to the lattice accommodation and to the activation of more ionic intercalation sites. The discharges capacities are summarized in Table 8. 
Table 8
Discharge capacity for TCM thin
films at 9th galvanostatic
discharge, tested at a current density of $15.0 \mathrm{mAg}^{-1}$.

\begin{tabular}{|ll|}
\hline Sample & $\begin{array}{l}\text { Discharge Capacity } \\
\left(\mathrm{mAhg}^{-1}\right)\end{array}$ \\
\hline $\mathrm{Po}+\mathrm{Pr}+$ & $100 \pm 2$ \\
\hline $\mathrm{Po}-\mathrm{Pr}-$ & $250 \pm 2$ \\
\hline $\mathrm{Po}+\mathrm{Pr}-$ & $45 \pm 2$ \\
\hline Po-Pr+ & $180 \pm 2$ \\
\hline
\end{tabular}

Table 9 describes the effects exerted by deposition parameters on the discharge capacity. The high negative value of the power main effect (-167.1) indicates that an increase in this parameter would cause a decrease in the discharge capacity, whereas the opposite is valid for the pressure (since it exhibited a positive value). Due to its high value, the power effect exerted more influence on the response of the discharge capacity. On the other hand, as far as roughness is concerned, the interaction effect was positive, showing a synergistic interaction between Po and Pr. In this case, though, the positive value demonstrates that both parameters directly influenced the response.

Table 9

Table of effects for the $2^{2}$ factorial design of the discharge capacity $\left(\mathrm{mAhg}^{-1}\right)$, at a current density of 15.0 $\mathrm{mAg}^{-1}$

\begin{tabular}{|lll|}
\hline & Effects & $\begin{array}{l}\text { Discharge Capacity } \\
\left(\mathbf{m A h g}^{-1} \text { ) }\right.\end{array}$ \\
\hline \multirow{2}{*}{ Main Effects } & Power & $-167.1 \pm 3.0$ \\
\cline { 2 - 3 } & Pressure & $53.4 \pm 3.0$ \\
\hline Interaction & Power-Pressure & $25.0 \pm 3.0$ \\
\hline
\end{tabular}

The highest capacity was observed in films deposited with lower power (Po-), demonstrating its dependency on physical properties, like crystallite size and roughness. A small crystallite size improves the kinetic performance, whereas the elevated roughness can generate a greater number of lithium diffuser channels and expand the contact area between the film and the electrolyte, improving the diffusion of lithium ions in the material and increasing its charge capacity [38, 39]. 


\section{Conclusions}

In this work, we investigated the correlation between the deposition parameters of RF magnetron sputtering and the electrochemical response of thin films synthetized with lithium ternary transition metal oxides $\left(\mathrm{LiMO}_{2}, \mathrm{M}=\mathrm{Mn}, \mathrm{Co}\right.$, and $\left.\mathrm{Ni}\right)$ at $4.20 \mathrm{~V}$, using a $2^{2}$ factorial design of experiments.

The films and the sputtering target did not exhibit the same elemental composition. However, with basis on electrochemical results, it became evident that, even with an excessive amount of manganese, the delivered discharge capacity of $250 \mathrm{mAhg}^{-1}$ was almost two times higher than that of traditional bulk LiCoO2, even when limiting the cell potential to $4.20 \mathrm{~V}$ during the charging process.

High discharge capacity was obtained within the potential window conventionally used in LIB's, with no need of additional thermal treatments. Such conditions favor the manufacture of RF magnetron sputtered TCM films on polymeric substrates, typically employed in flexible devices.

\section{Declarations}

\section{Funding}

This article was partially supported by the following funding agencies: Conselho Nacional de Pesquisa (CNPq) and Coordenação de Aperfeiçoamento de Pessoal de Nível Superior (CAPES), which contributed with the financial support for this work, and Financiadora de Estudos e Projetos (FINEP), for providing equipment infrastructure.

\section{Conflicts of interest/Competing interests}

The authors declare that there is no conflict of interest.

\section{Availability of data and material}

The data of this work are available upon request to the corresponding author.

\section{Code availability}

Not applicable

\section{Authors' contributions}

All authors contributed to the study concept and design. Material preparation, data collection and analyses were performed by [Daniel Andres Sanchez Lopez], [Luciana Gomes Chagas], [Aline Domingues Batista], [Maria Gabriella Detone Guaita], [Luís Henrique Cardozo Amorin], [Paulo Rogério Catarini da Silva], [Gustavo Yamanishi], [Dimas Augusto Morozin Zaia], [Henrique de Santana] and [Alexandre Urbano]. The first draft of the manuscript was written by [Daniel Andres Sanchez Lopez and Alexandre 
Urbano]. All authors commented on previous versions of the article, and read and approved the final manuscript.

\section{Acknowledgments}

Laboratory of Thin Films and Materials (FILMAT), Department of Physics of UEL; General Inorganic Chemistry Laboratory and Physical Chemistry Laboratory, Department of Chemistry of UEL; Multi-user LARX/UEL (Lab. of X-Ray analysis), LMEM/UEL (Lab. of microscopy and microanalysis) and SPEC/UEL (Lab. of spectroscopy).

\section{References}

1. K. Mizushima, P.C. Jones, P.J. Wiseman, J.B. Goodenough, Solid State lonics 3-4, 171 (1981)

2. Y. I. and K. Hi, A. Tsutomu Ohzuku, M. Ueda, Nagayama, Electrochem. Acta 38, 1159 (1993)

3. T. Ohzuku, S. Kitano, M. Iwanaga, H. Matsuno, A. Ueda, J. Power Sources 68, 646 (1997)

4. Y. Makimura, T. Ohzuku, 121, 156 (2003)

5. M.Y. Song, E.Y. Bang, D.R. Mumm, H.R. Park, Ceram. Int. 38, 4953 (2012)

6. T. Ohzuku, Y. Makimura, Chem. Lett. 30, 642 (2001)

7. J.M. Kim, H.T. Chung, Electrochim. Acta 49, 937 (2004)

8. Y.-S. Lee, K.-S. Lee, Y.-K. Sun, Y.M. Lee, D.-W. Kim, J. Power Sources 196, 6997 (2011)

9. J. Chen, N. Zhao, G.D. Li, F.F. Guo, J. Zhao, Y. Zhao, T. Jia, F. Fu, J. Li, Mater. Res. Bull. 73, 192 (2016)

10. L. Li, L.C. Wang, X.X. Zhang, M. Xie, F. Wu, R.J. Chen, ACS Appl. Mater. Interfaces 7, 21939 (2015)

11. H.J. Noh, S. Youn, C.S. Yoon, Y.K. Sun, J. Power Sources 233, 121 (2013)

12. J.P. Hu, H. Sheng, Q. Deng, Q. Ma, J. Liu, X.W. Wu, J.J. Liu, Y.P. Wu, Energies 13, 1 (2020)

13. W. Yan, Y. Liu, S. Chong, Y. Zhou, J. Liu, Z. Zou, Prog. Chem. 29, 198 (2017)

14. E. Zhao, M. Chen, Z. Hu, D. Chen, L. Yang, X. Xiao, J. Power Sources 343, 345 (2017)

15. H. Zheng, Q. Sun, G. Liu, X. Song, V.S. Battaglia, J. Power Sources 207, 134 (2012)

16. S. Zhang, J. Ma, Z. Hu, G. Cui, L. Chen, Chem. Mater. 31, 6033 (2019)

17. J. Zhu, K. Yoo, A. Denduluri, W. Hou, J. Guo, D. Kisailus, J. Mater. Res. 30, 286 (2014)

18. S. Cui, Y. Wei, T. Liu, W. Deng, Z. Hu, Y. Su, H. Li, M. Li, H. Guo, Y. Duan, W. Wang, M. Rao, J. Zheng, X. Wang, F. Pan, Adv. Energy Mater. 6, 1 (2016)

19. J.J. Ding, Q. Sun, Z.W. Fu, Electrochem. Solid-State Lett. 13, 108 (2010)

20. J. Xie, N. Imanishi, T. Zhang, A. Hirano, Y. Takeda, O. Yamamoto, J. Power Sources 195, 5780 (2010) 21. H.G. Wang, W. Li, D.P. Liu, X.L. Feng, J. Wang, X.Y. Yang, X.B. Zhang, Y. Zhu, Y. Zhang, Adv. Mater. 29, 1 (2017)

22. Z. Liu, J. Xu, D. Chen, G. Shen, Chem. Soc. Rev. 44, 161 (2015)

23. X. Cao, Y. Zhao, L. Zhu, L. Xie, X. Cao, S. Xiong, C. Wang, Chem. Lett. 11, 5267 (2016) 
24. B. Barros Neto, I.S. Scarminio, R.E. Bruns, Como Fazer Experimentos: Pesquisa e Desenvolvimento Na Ciência e Na Indústria (Second (Editora da Unicamp, Campinas, 2001)

25. M.R.M. Marinho, W.B. Castro, XXXIII - Congr. Bras. Ensino Eng. 1 (2005)

26. K.M. Shaju, G.V.S. Rao, and B. V. R. Chowdari 48, 145 (2002)

27. Z. Hu, Z. Deng, Q. Wei, T. Zhao, Y. Wang, Z. Yu, L. Ma, K. Zhou, lonics (Kiel). 23, 2981 (2017)

28. J.B. Bates, N.J. Dudney, B.J. Neudecker, F.X. Hart, H.P. Jun, S.a. Hackney, J. Electrochem. Soc. 147, 59 (2000)

29. F.M. Mwema, O.P. Oladijo, S.A. Akinlabi, E.T. Akinlabi, J. Alloys Compd. 747, 306 (2018)

30. B. Ramkumar, S. Yuvaraj, S. Surendran, K. Pandi, H.V. Ramasamy, Y.S. Lee, R. Kalai, Selvan, J. Phys. Chem. Solids 112, 270 (2018)

31. L. Yao, H. Yao, G. Xi, Y. Feng, RSC Adv. 6, 17947 (2016)

32. A.M. Hashem, R.S. El-tawil, M. Abutabl, A.E. Eid, Res. Eng. Struct. Mater. (2015)

33. A. Nichelson, K. Karuppasamy, S. Thanikaikarasan, P. Anil Reddy, P. Kollu, S. Karthickprabhu, and X. Sahaya Shajan, lonics (Kiel). 24, 1007 (2018)

34. G. Zhang, B. Qiu, Y. Xia, X. Wang, Q. Gu, Y. Jiang, Z. He, J. Power Sources 420, 29 (2019)

35. V.A.C. Haanappel, D.v.d Vendel, H.D. van Corbach, T. Fransen, P.J. Gellings, Thin Solid Films 256, 8 (1995)

36. P. Pasierb, S. Komornicki, M. Rokita, M. Rekas, J. Mol. Struct. 596, 151 (2001)

37. P. Barboux, J.M. Tarascon, F.K. Shokoohi, R. Bank, J. Solid State Chem. 94, 185 (1991)

38. M. Strafela, H. Leiste, K. Seemann, H.J. Seifert, S. Ulrich, Vaccum 131, 240 (2016)

39. B. Deng, Z. Lin, Y. Chen, W. He, J. Wang, Q. Xie, L. Wang, D.L. Peng, J. Alloys Compd. 834, 1 (2020)

\section{Figures}




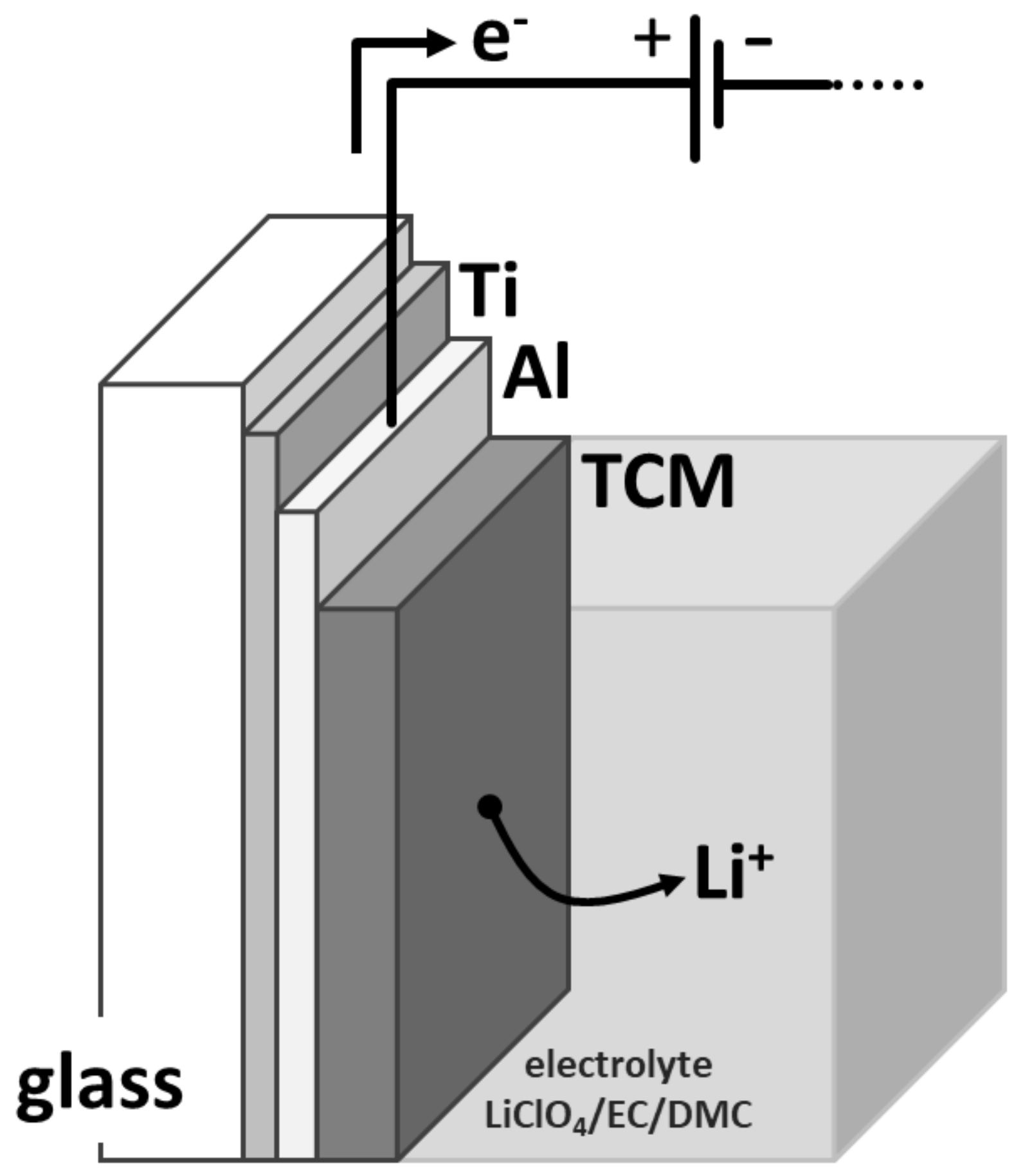

Figure 1

Half electrochemical cell illustration, portraying the monolithic arrangement of $\mathrm{Ti}, \mathrm{Al}$ and TCM thin films onto glass substrate 

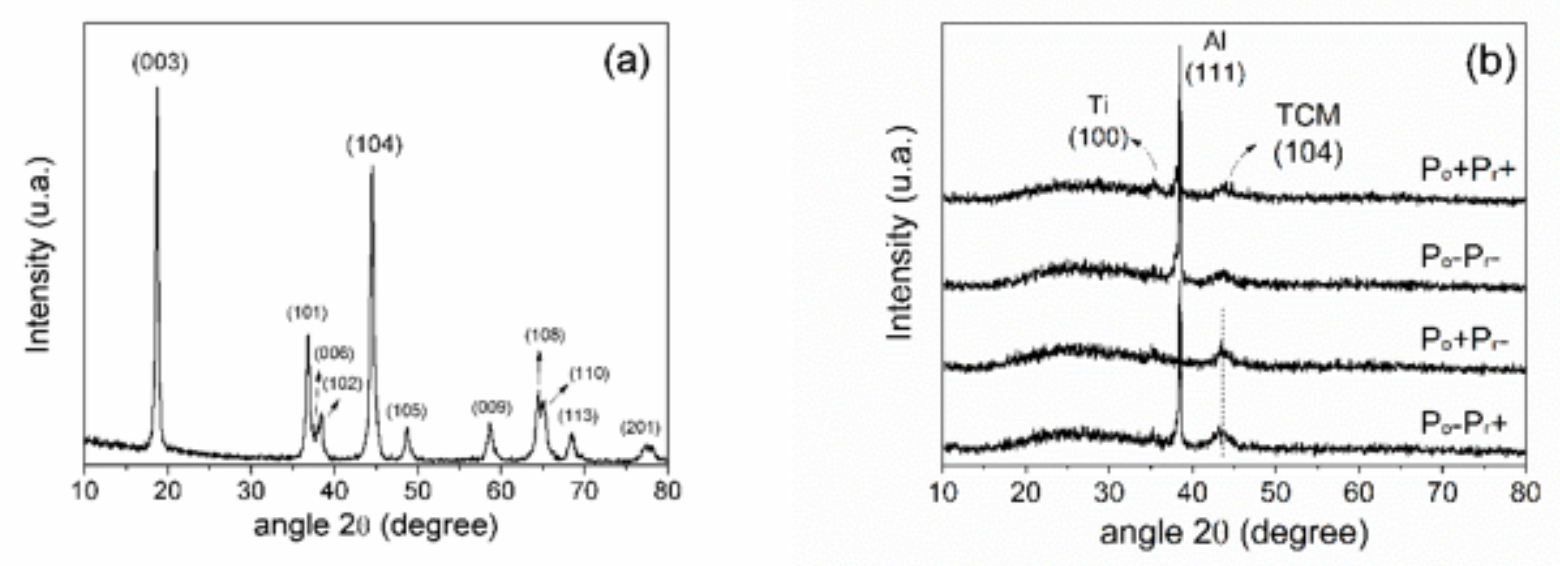

\section{Figure 2}

Diffraction patterns of a) LiNi1/3Mn1/3Co1/302, prepared via sol-gel method and calcined in the air for $6 \mathrm{~h}$ at $700{ }^{\circ} \mathrm{C}$, and b) ternary oxide thin films (TCM), deposited in accordance with the planning illustrated in table 1
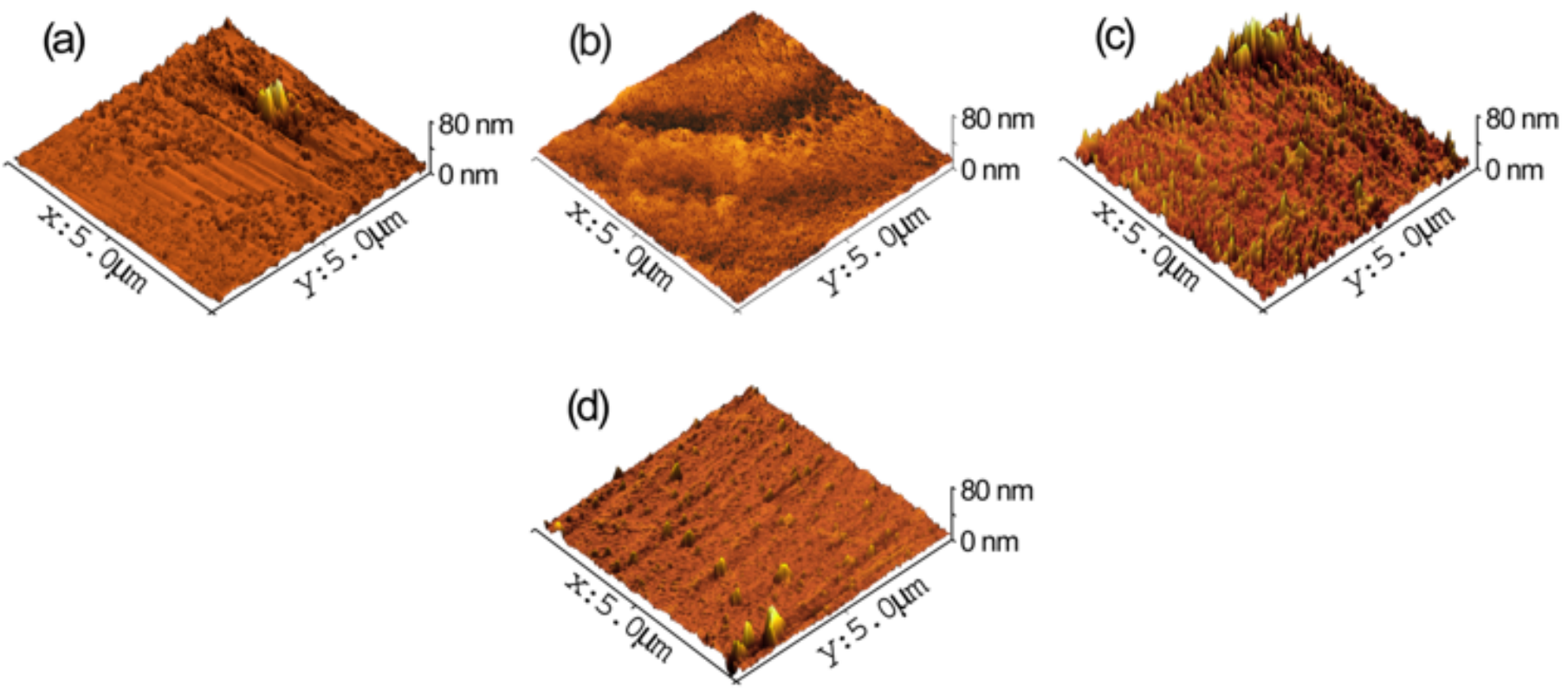

\section{Figure 3}

Surface AFM images for: a) glass, b) glass/Ti, c) glass/Al and d) glass/Ti/Al 

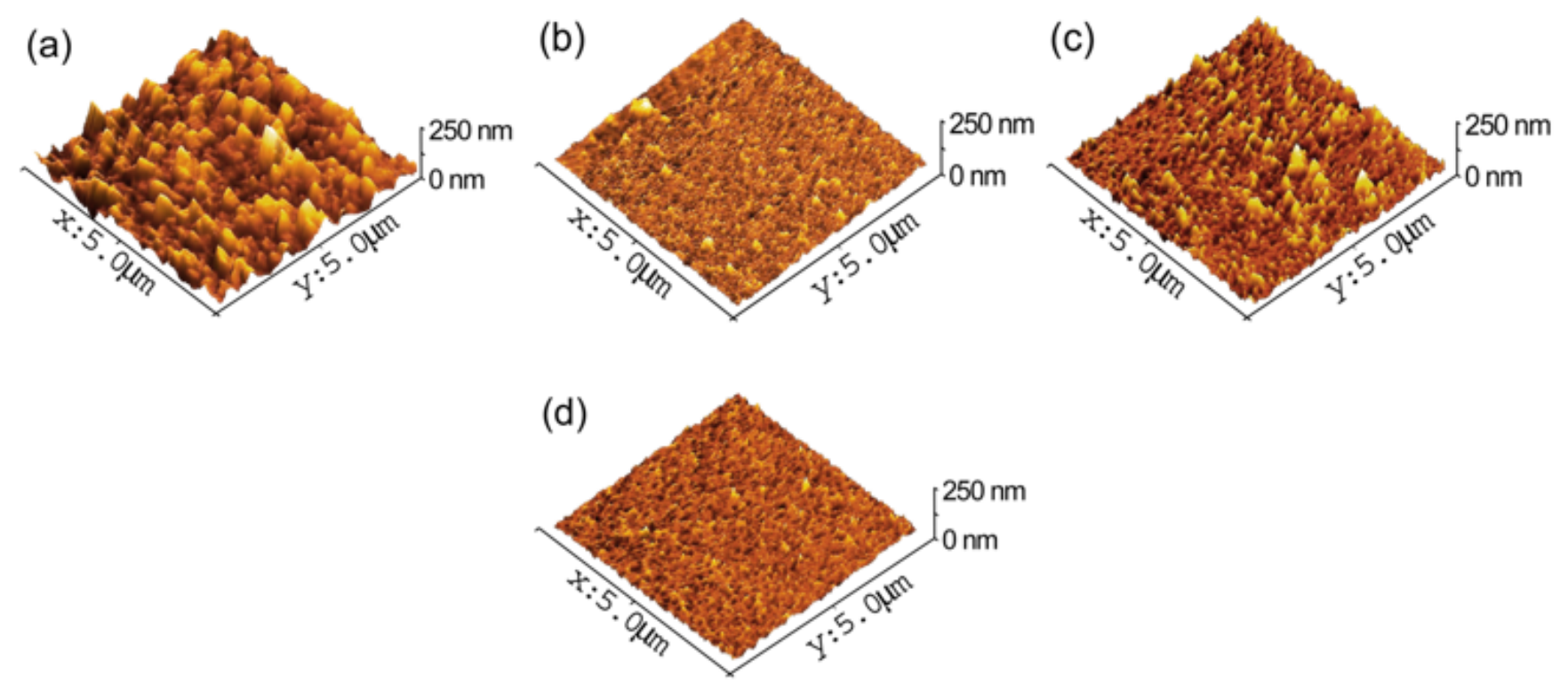

\section{Figure 4}

Atomic force micrographs of the surface morphology of TCM films. (a) Po-Pr+, (b) Po+Prt, (c) Po-Pr-, and (d) Po+Pr-. All films were deposited on glass/Ti/Al substrate 


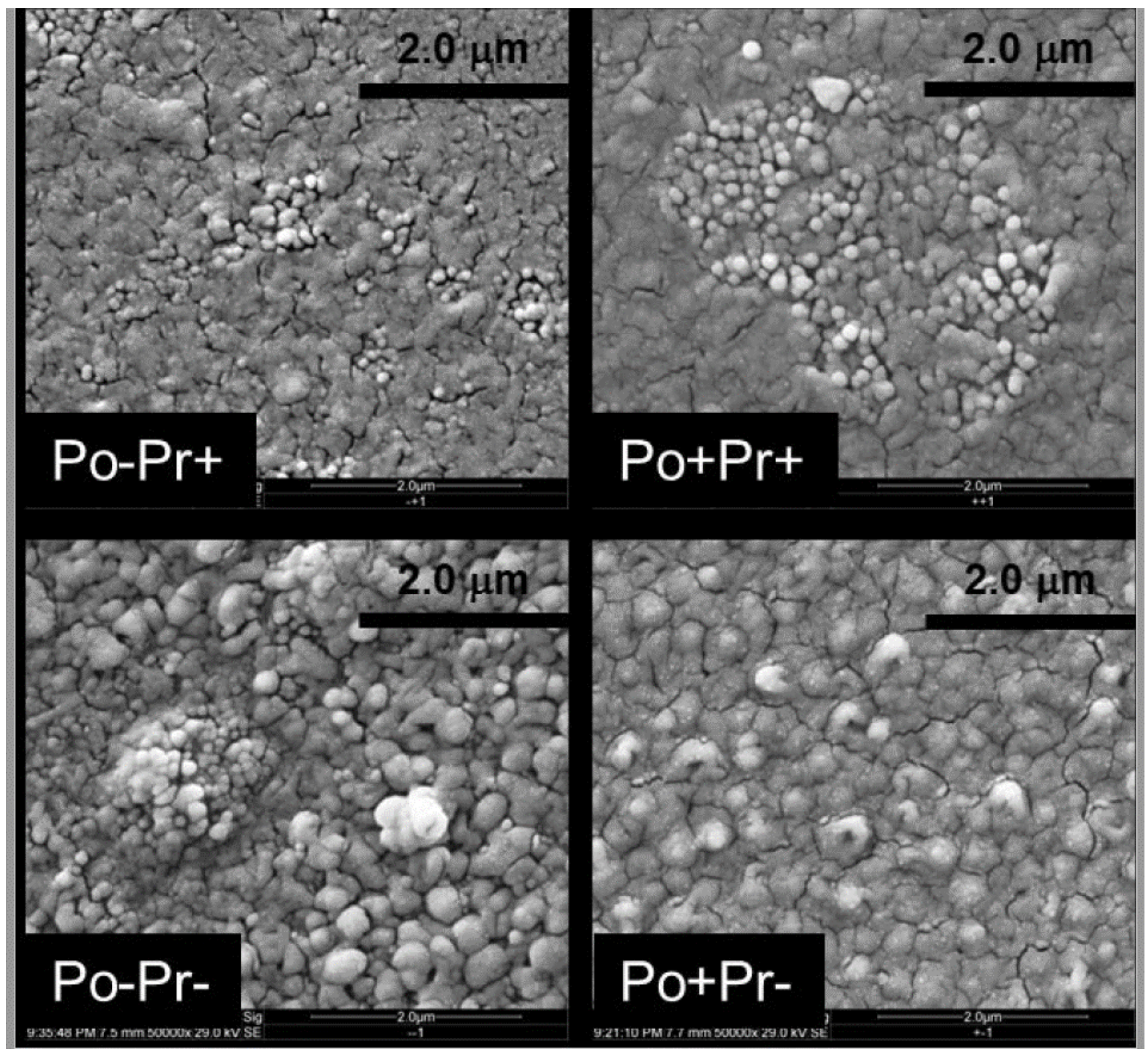

Figure 5

SEM images of TCM thin films deposited by RF magnetron sputtering, obtained from a 22 factorial design. The black bar represents a $2 \mu \mathrm{m}$ scale 


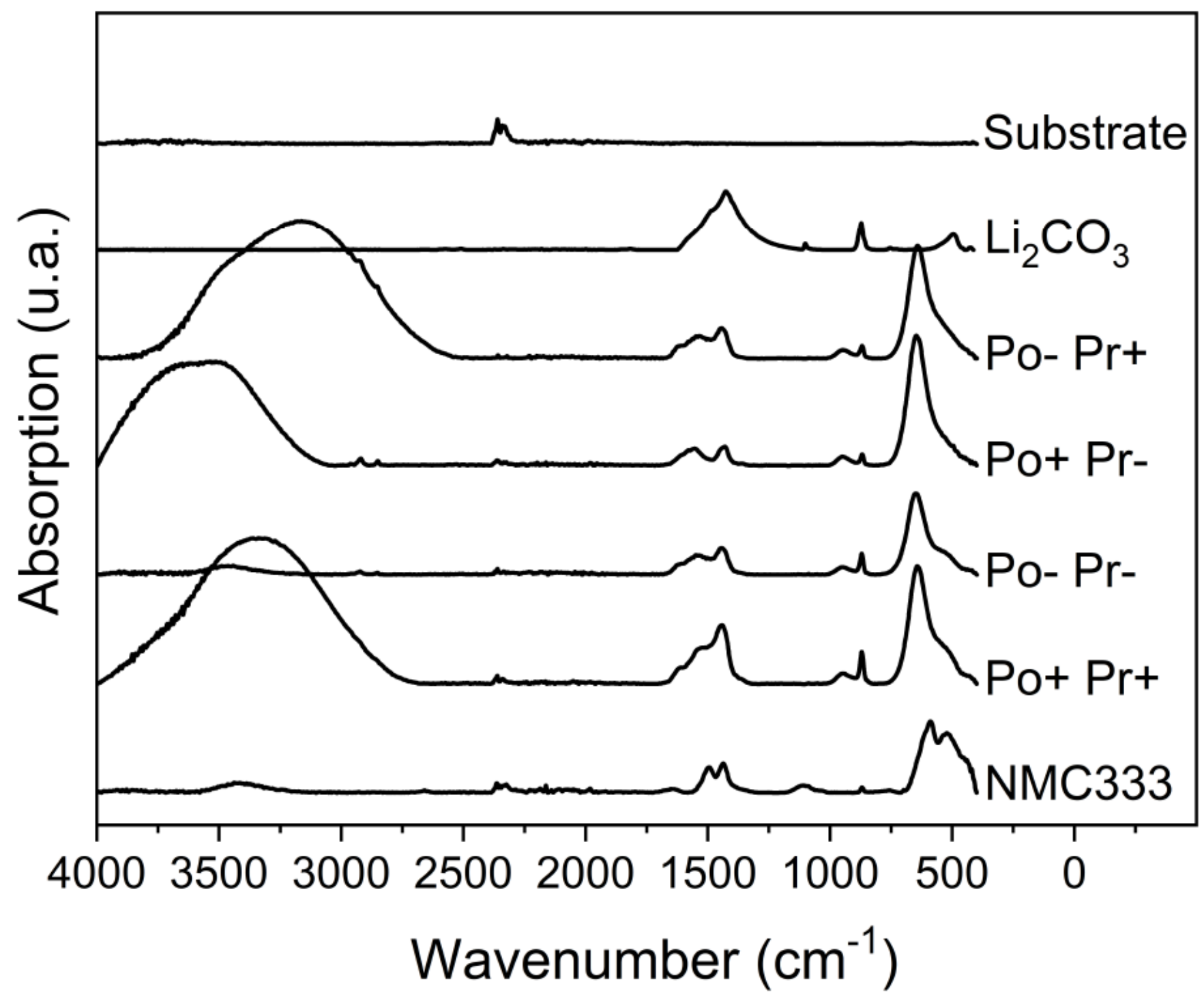

Figure 6

FTIR spectra of NMC333 powder, NMC Po $\pm P r \pm$ films, glass/Ti/Al substrate and lithium carbonate 

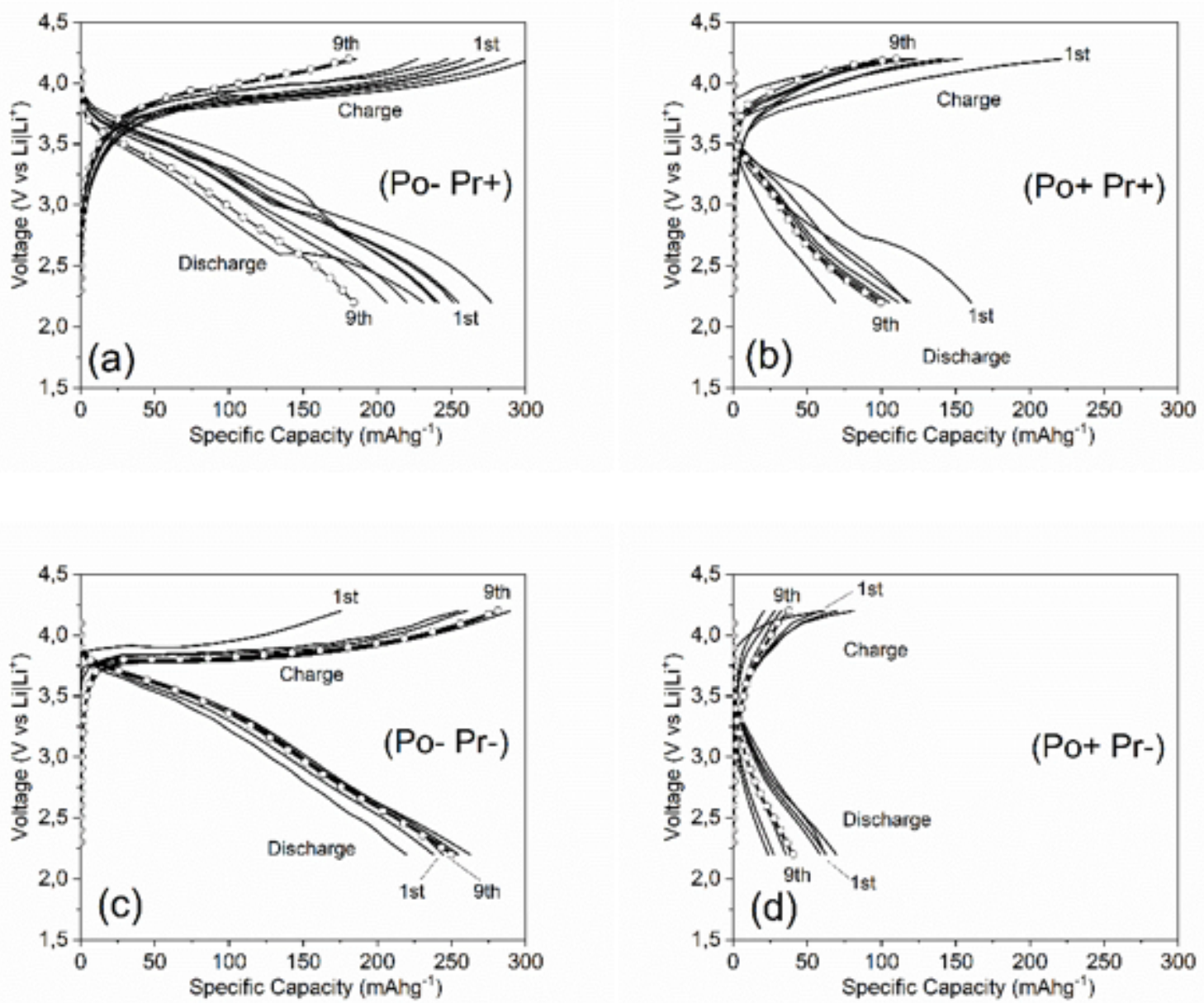

\section{Figure 7}

Chronopotentiometric charge and discharge cycles of TCM films, tested at a current density of $15.0 \mathrm{mAg}$ 1. 